\title{
PERANCANGAN MOBILE LEARNING MATA KULIAH SISTEM OPERASI BERBASIS ANDROID
}

\author{
Tri Listyorini \\ Dosen Fakultas Teknik, Program Studi Teknik Informatika \\ Universitas Muria Kudus \\ Email: trilistyorini.ti.umk@gmail.com \\ Anteng Widodo \\ Dosen Fakultas Teknik, Program Studi Sistem Informasi \\ Universitas Muria Kudus \\ Email: antengwidodo@gmail.com
}

\begin{abstract}
ABSTRAK
Sistem operasi sekarang ini menjadi salah satu bagian dari kurikulum program studi yang mengatas namakan teknologi informasi. Karena mata kuliah sistem operasi merupakan dasar dari pengenalan sebuah perangkat, baik itu komputer maupun ponsel. Proses belajar mengajar dapat dilakukan di mana saja dan kapan saja. Seiring dengan perkembangan teknologi informasi, teknologi ponsel atau telepon genggam juga mengalami peningkatan yang pesat. Hal ini dibuktikan dengan banyak siswa yang menjadikan ponsel tersebut sebagai alat pembelajaran. Pembelajaran mengalami perpindahan yang semula konvensional menjadi E-Learning. Aplikasi Mobile Learning ini berisi informasi, chat, kuis, kursus, forum atau yang lain.

Kata kunci: sistem operasi, android, m-learning, e-learning
\end{abstract}

\section{ABSTRACT}

The operating system now has become a part of the course curriculum of information technology in their name. Because of course the operating system is the basis of the introduction of a device, be it a computer or mobile phone. The process of teaching and learning can be done anywhere and anytime. Along with the development of information technology, mobile phones or mobile phones also increased rapidly. This is evidenced by the many students who make the mobile phone as a learning tool. Learning experience of the original displacement of conventional E-Learning. Learning mobile application contains information, chat, quizzes, courses, forums or the other.

Keywords: operating system, android, m-learning, e-learning

\section{PENDAHULUAN}

Perkembangan teknologi sekarang ini sangat pesat, hal ini juga diikuti dengan perkembangan ponsel yang didalamnya terdapat beraneka sistem operasi. Salah satu sistem operasi yang laris digunakan di ponsel atau smartphone adalah sistem operasi android. Sistem operasi merupakan jenis yang paling penting dari perangkat lunak sistem dalam sistem komputer. Tanpa sistem operasi, pengguna tidak dapat menjalankan program aplikasi pada ponsel, kecuali program aplikasi booting.

Sistem operasi sekarang ini menjadi salah satu bagian dari kurikulum program studi yang mengatas namakan teknologi informasi. Karena mata kuliah sistem operasi merupakan dasar dari pengenalan sebuah perangkat, baik itu komputer maupun ponsel. Pada kenyataannya, pengajaran mata kuliah sistem operasi masih menggunakan cara transfer ilmu dari pengajar ke siswa secara langsung di kelas. Siswa hanya menjadi objek pasif yang mendengarkan dan menghafal materi yang disampaikan oleh pengajar.

Mobile Learning merupakan model pembelajaran yang memanfaatkan teknologi informasi dan komunikasi. Pada konsep pembelajaran tersebut Mobile Learning membawa manfaat ketersediaan materi ajar yang dapat diakses setiap saat dan visualisasi materi yang menarik. Hal penting yang perlu diperhatikan bahwa tidak setiap materi pengajaran cocok memanfaatkan Mobile Learning.

Mobile learning atau m-learning sering didefinisikan sebagai e-learning melalui perangkat komputasi mobile. Mobile Learning juga merupakan penyampaian bahan pembelajaran elektronik pada alat komputasi mobile agar dapat diakses darimana saja dan kapan saja [1]. Pada umumnya, perangkat mobile berupa telepon seluler digital dan PDA. Namun, secara lebih umum dapat didefinisikan sebagai perangkat apapun yang berukuran cukup kecil, dapat bekerja sendiri, dapat dibawa setiap waktu dalam kehidupan sehari-hari, dan yang dapat digunakan untuk beberapa bentuk pembelajaran. Perangkat kecil ini dapat dilihat sebagai alat untuk mengakses konten, baik disimpan secara local pada device maupun dapat dijangkau melalui interkoneksi. Perangkat ini juga dapat menjadi alat untuk berinteraksi dengan 
orang lain, baik melalui suara, maupun saling bertukar pesan tertulis, gambar diam dan gambar bergerak. Dengan Mobile Learning pembelajaran mata kuliah sistem operasi menjadi lebih efektif, interaktif, dan edukatif.

\section{PERUMUSAN MASALAH}

Berdasarkan pada latar belakang, maka dapat dirumuskan permasalahan :

a. Kebutuhan akan teknologi dalam proses pembelajaran lebih mudah, menarik dan efisien. Hal ini akan menciptakan proses pembelajaran mata kuliah sistem operasi menjadi lebih menarik dan dapat di akses di mana saja dan kapan saja.

b. Memanfaatkan teknologi ponsel dengan sistem operasi yang open source. Dengan ditambahkannya Mobile Learning, ponsel tidak hanya untuk alat komunikasi saja, namun menjadi media pembelajaran yang sangat diminat oleh siswa.

c. Banyaknya siswa yang sudah menggunakan ponsel berbasis android, oleh karena itu pengembangan media pembelajaran beralih ke Mobile Learning.

\section{TUJUAN DAN MANFAAT}

Tujuan dan Manfaat Mobile Learning ini : Adapun tujuan dari penelitian ini adalah :

a. Menerapkan Mobile Learning berbasis android pada mata kuliah sistem operasi.

b. Merancang Mobile Learning berbasis android pada smart phone.

c. Mengembangkan bahan ajar Mobile Learning berbasis android

Adapun manfaat dari Mobile Learning ini adalah :

a. Meningkatkan kemampuan Universitas Muria Kudus dalam penelitian, pengembangan dan penerapan IPTEKS.

b. Meningkatkan konstribusi Universitas Muria Kudus dalam pembangunan pendidikan di Jawa Tengah

c. Menghasilkan bahan ajar Mobile Learning berbasis android

\section{LANDASAN TEORI}

\subsection{Sistem Operasi}

Sistem operasi (bahasa Inggris: operating system ; OS) adalah seperangkat program yang mengelola sumber daya perangkat keras komputer, dan menyediakan layanan umum untuk aplikasi perangkat lunak. Sistem operasi adalah jenis yang paling penting dari perangkat lunak sistem dalam sistem komputer. Tanpa sistem operasi, pengguna tidak dapat menjalankan program aplikasi pada komputer mereka, kecuali program aplikasi booting.

Sistem operasi mempunyai penjadwalan yang sistematis mencakup perhitungan penggunaan memori, pemrosesan data, penyimpanan data, dan sumber daya lainnya.

Untuk fungsi-fungsi perangkat keras seperti sebagai masukan dan keluaran dan alokasi memori, sistem operasi bertindak sebagai perantara antara program aplikasi dan perangkat keras komputer [2], meskipun kode aplikasi biasanya dieksekusi langsung oleh perangkat keras dan seringkali akan menghubungi OS atau terputus oleh itu. Sistem operasi yang ditemukan pada hampir semua perangkat yang berisi komputer-dari ponsel dan konsol permainan video untuk superkomputer dan server web. $\quad$ Contoh sistem operasi modern adalah Linux, Android, iOS, Mac OS X, dan Microsoft Windows. Kedudukan sistem operasi berada diantara aplikasi dan perangkat keras seperti terlihat pada gambar 1.

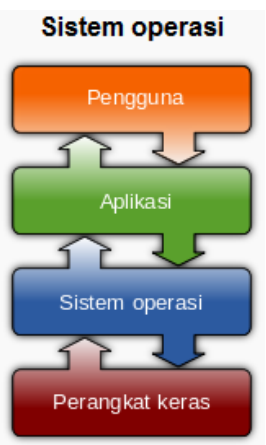

Gambar 1. Kedudukan sistem operasi

\subsection{Android}

Android adalah sistem operasi yang berbasis Linux untuk telepon seluler seperti telepon pintar dan komputer tablet. Android menyediakan platform terbuka bagi para pengembang untuk menciptakan aplikasi mereka sendiri untuk 
digunakan oleh bermacam peranti bergerak. Awalnya, Google Inc. membeli Android Inc., pendatang baru yang membuat peranti lunak untuk ponsel. Kemudian untuk mengembangkan Android, dibentuklah Open Handset Alliance, konsorsium dari 34 perusahaan peranti keras, peranti lunak, dan telekomunikasi, termasuk Google, HTC, Intel, Motorola, Qualcomm, T-Mobile, dan Nvidia.

Pada saat perilisan perdana Android, 5 November 2007, Android bersama Open Handset Alliance menyatakan mendukung pengembangan standar terbuka pada perangkat seluler. Di lain pihak, Google merilis kode-kode Android di bawah lisensi Apache, sebuah lisensi perangkat lunak dan standar terbuka perangkat seluler.

Di dunia ini terdapat dua jenis distributor sistem operasi Android. Pertama yang mendapat dukungan penuh dari Google atau Google Mail Services (GMS) dan kedua adalah yang benar-benar bebas distribusinya tanpa dukungan langsung Google atau dikenal sebagai Open Handset Distribution (OHD).

Fitur-fitur pada Android antara lain adalah :

a. Framework aplikasi, memungkinkan daur ulang dan penggantian komponen.

b. Browser terintegrasi berbasis engine Open Source WebKit yang juga digunakan di browser IPhone dan Nokia S60v3.

c. Rancangan handset. Platform disesuaikan dengan kebutuhan VGA (Video Graphics Adapter) yang lebih besar, library grafik 2D dan 3D yang berdasarkan pada spesifikasi OpenGL ES 1.0 serta layout smartphone yang tradisional.

d. Multi-touch. Android memiliki dukungan bawaan untuk multi-touch yang tersedia pada handset terbaru seperti HTC Hero.

e. Dukungan hardware tambahan. Android mendukung penggunaan kamera, layar sentuh, GPS (Global Positioning System), pengukur kecepatan, magnetometer, akselerasi 2D bit blits (dengan orientasi hardware, scaling, konversi format piksel) dan akselerasi grafis 3D.

\subsection{Mobile Learning}

Mobile Learning didefinisikan oleh Clark Quinn (2000) sebagai The intersection of mobile computing and e-learning: accessible resources wherever you are, strong search capabilities, rich interaction, powerful support for effective learning, and performance-based assessment. E-Learning independent of location in time or space.

Merujuk dari definisi tersebut maka, Mobile Learning adalah model pembelajaran yang memanfaatkan teknologi informasi dan komunikasi, seperti contoh pada gambar 2. Pada konsep pembelajaran tersebut Mobile Learning membawa manfaat ketersediaan materi ajar yang dapat diakses setiap saat dan visualisasi materi yang menarik. Hal penting yang perlu diperhatikan bahwa tidak setiap materi pengajaran cocok memanfaatkan Mobile Learning[4].

Stevanus Wisnu Wijaya menjelaskan bahwa materi ajar yang tidak cocok mengadopsi konsep Mobile Learning antara lain: materi yang bersifat hands on, keterampilan sebagaimana dokter gigi, seni musik khususnya mencipta lagu, interview skills, team work seperti marketing maupun materi yang membutuhkan pengungkapan ekspresi seperti tarian [3]. Mempertimbangkan hal-hal tersebut di atas maka penerapan Mobile Learning lebih baik pada jenjang pendidikan tinggi.

Mobile learning atau m-learning sering didefinisikan sebagai e-learning melalui perangkat komputasi mobile. Mobile Learning juga merupakan penyampaian bahan pembelajaran elektronik pada alat komputasi mobile agar dapat diakses darimana saja dan kapan saja [1]. Pada umumnya, perangkat mobile berupa telepon seluler digital dan PDA. Namun, secara lebih umum dapat didefinisikan sebagai perangkat apapun yang berukuran cukup kecil, dapat bekerja sendiri, dapat dibawa setiap waktu dalam kehidupan sehari-hari, dan yang dapat digunakan untuk beberapa bentuk pembelajaran. Perangkat kecil ini dapat dilihat sebagai alat untuk mengakses konten, baik disimpan secara local pada device maupun dapat dijangkau melalui interkoneksi. Perangkat ini juga dapat menjadi alat untuk berinteraksi dengan orang lain, baik melalui suara, maupun saling bertukar pesan tertulis, gambar diam dan gambar bergerak.

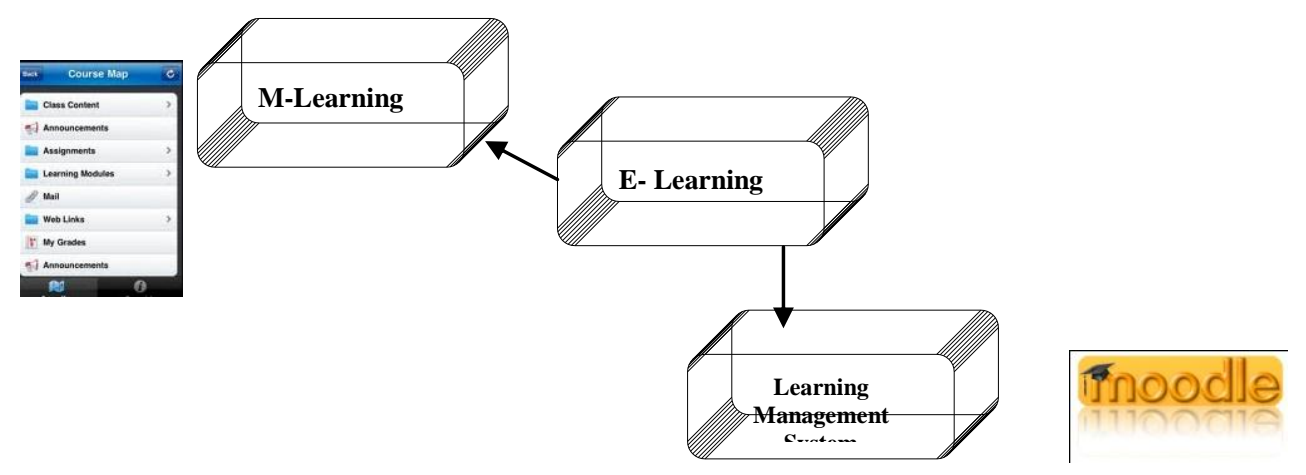

Gambar 2. Mobile Learning 


\section{METODOLOGI PENELITIAN}

Metode yang digunakan dalam penelitian ini adalah metode penelitian pengembangan (research and development), dimana desain pengembangan yang dipilih adalah menggunakan Model Dick dan Carey (1990) (dikutip dari Santyasa, 2009). Karena luaran utama yang akan dihasilkan dalam penelitian berupa sebuah perangkat lunak, maka dalam proses pengembangan media akan dilengkapi dengan metode khusus pengembangan perangkat lunak dengan menggunakan metode Software Development Life Cycle (SDLC) dengan Waterfall-based Model seperti gambar 3.

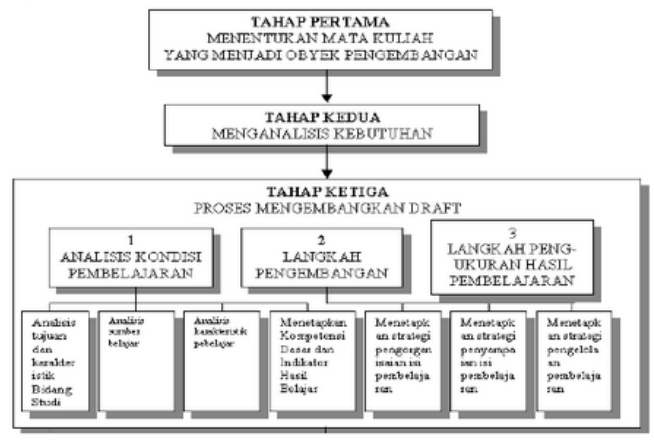

Gambar 3 Tahap Pertama, Kedua dan Ketiga Desain Pengembangan Media

Karena media yang dikembangkan dalam penelitian pengembangan ini akan menghasilkan produk akhir berupa perangkat lunak program simulasi, maka tahap ketiga akan dilanjutkan dengan tahap keempat daridesain pengembangan ang diadaptasikan dengan metode pengembangan perangkat lunak yaitu metode Software Development Life Cycle (SDLC) dengan Waterfall Model. Metodologi SDLC ini merupakan metodologi untuk menganalisis dan merancang sebuah sistem secara terstruktur. Metodologi SDLC terdiri dari beberapa tahap seperti gambar 4 .

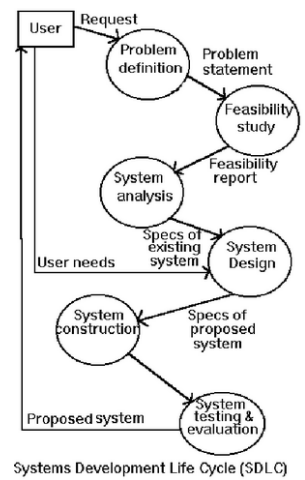

Gambar 4 Diagram SDLC

Tahap kelima yang merupakan tahap terakhir dari desain pengembangan media pembelajaran, dimana pada tahap ini dilakukan pengujian perangkat lunak sebagai media pembelajaran yang meliputi : pengujian ahli media, pengujian ahli isi, pengujian kelompok kecil dan uji coba lapangan, yang disajikan dalam gambar 5 berikut ini : 


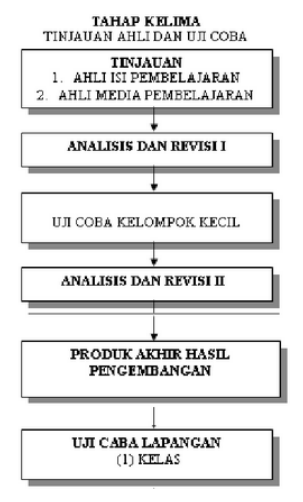

Gambar 5 Tahap Kelima Desain Pengembangan Draft

\section{DESAIN PERANCANGAN SISTEM}

Desain perancangan sistem Mobile Learning pada mata kuliah sistem operasi ini adalah menggunakan use case diagram dan activity diagram.

\subsection{Use Case Diagram}

Sistem yang dirancang memiliki enam buah Use Case utama, yaitu Pendahuluan, Tujuan Pembelajaran, Arsitektur Sistem Operasi (SO), Kategori Sistem Operasi (SO), Tugas Individu dan Referensi. Selain itu terdapat empat buah Use Case tambahan, yaitu Pengertian Sistem Operasi, manfaat sistem operasi yang merupakan turunan dari Pendahuluan. Aktor tunggal yang berperan dalam sistem adalah User. User (pengguna) dapat memilih salah satu dari enam menu utama yang ada, yaitu Pendahuluan, Tujuan Pembelajaran, Arsitektur Sistem Operasi, Kategori Sistem Operasi, Tugas Individu dan Referensi. Menu Pendahuluan berisi mengenai pengertian sistem operasi dan manfaat sistem operasi. Menu Tujuan Pembelajaran berisi tujuan dari pembelajaran. Menu Arsitektur Sistem Operasi berisi materi tentang arsitektur sistem operasi. Menu Kategori sistem operasi berisi materi tentang kategori sistem operasi. Menu Tugas Individu berisi tugas dalam bentuk soal uraian beserta Petunjuk untuk mengerjakannya. Menu Referensi berisi daftar sumber pustaka rujukan. Use Case Diagram dari sistem digambarkan pada Gambar 6.

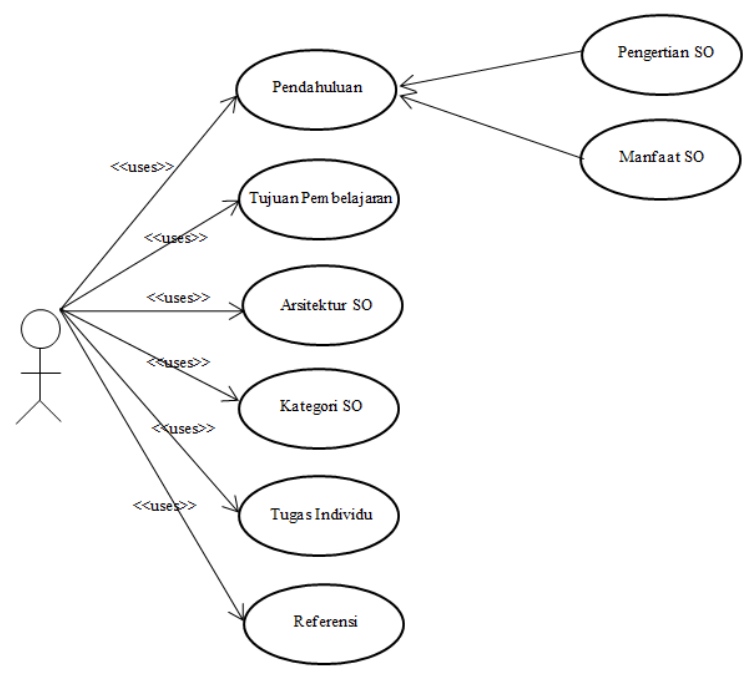

Gambar 6 Use Case Diagram Perancangan Mobile Learning

\subsection{Activity Diagram}

Activity Diagram merupakan bagian dari penggambaran sistem secara fungsional karena di dalamnya dijelaskan tentang proses-proses logika atau fungsi yang terimplementasi oleh kode program. Gambar 7 akan menggambarkan Activity Diagram dari perancangan mobile learning pada mata kuliah sistem operasi. 


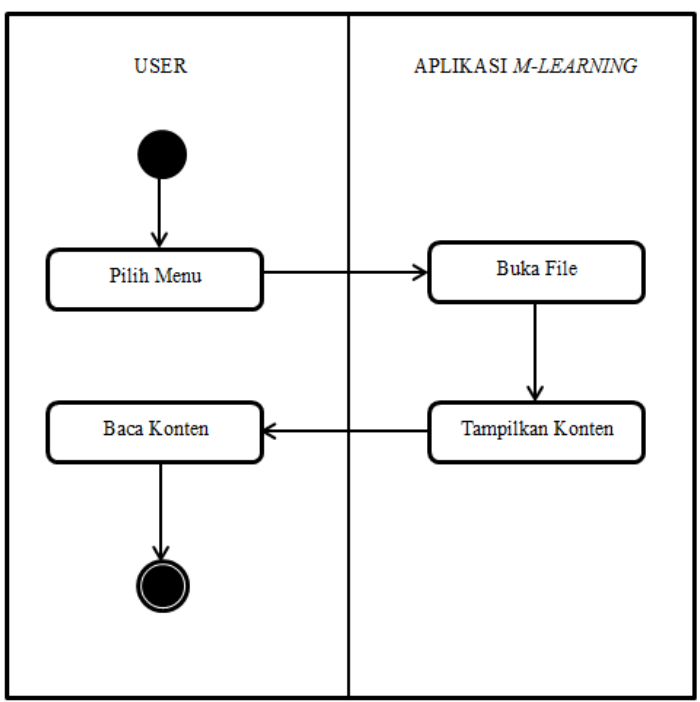

Gambar 7 Activity Diagram Perancangan Mobile Learning

\section{DAFTAR PUSTAKA}

[1] Ally, Mohamed. (2009). Mobile Learning Transforming the Delivery of Education and Training. Atabasca University: AU Press.

[2] Stallings (2005). Operating Systems, Internals and Design Principles. Pearson: Prentice Hall. hlm. 6. Quinn, C. (2000). Mlearning, Mobile Wireless in Your Pocket Learning

[3] Wijaya, Stevanus Wisnu. Mobile Learning Sebagai Model Pembelajaran Alternatif Bagi Pemulihan Pendidikan Di Daerah Bencana Alam Gempa Bumi Yogyakarta. Universitas Sanata Dharma.

[4] Sri Nugraha, Aditya. (2010). Pengembangan dan Implementasi Mobile Learning Berbasis J2ME untuk Mata Pelajaran Keterampilan Komputer dan Pengelolaan Informasi. Pendidikan Ilmu Komputer UPI. Bandung 